\title{
Comparative Study of Ground Measured, Satellite-Derived, and Estimated Global Solar Radiation Data in Nigeria
}

\author{
Boluwaji M. Olomiyesan ${ }^{1}$ and Onyedi D. Oyedum ${ }^{2}$ \\ ${ }^{1}$ Examination Development Department, National Examinations Council (NECO), PMB 159, Minna 920211, Niger State, Nigeria \\ ${ }^{2}$ Department of Physics, Federal University of Technology, PMB 65, Minna 920211, Niger State, Nigeria \\ Correspondence should be addressed to Boluwaji M. Olomiyesan; olomiyebolu@yahoo.com
}

Received 12 March 2016; Revised 2 June 2016; Accepted 8 June 2016

Academic Editor: S. Silva-Martínez

Copyright ( 2016 B. M. Olomiyesan and O. D. Oyedum. This is an open access article distributed under the Creative Commons Attribution License, which permits unrestricted use, distribution, and reproduction in any medium, provided the original work is properly cited.

\begin{abstract}
In this study, the performance of three global solar radiation models and the accuracy of global solar radiation data derived from three sources were compared. Twenty-two years (1984-2005) of surface meteorological data consisting of monthly mean daily sunshine duration, minimum and maximum temperatures, and global solar radiation collected from the Nigerian Meteorological (NIMET) Agency, Oshodi, Lagos, and the National Aeronautics Space Agency (NASA) for three locations in North-Western region of Nigeria were used. A new model incorporating Garcia model into Angstrom-Prescott model was proposed for estimating global radiation in Nigeria. The performances of the models used were determined by using mean bias error (MBE), mean percentage error (MPE), root mean square error (RMSE), and coefficient of determination $\left(R^{2}\right)$. Based on the statistical error indices, the proposed model was found to have the best accuracy with the least RMSE values ( 0.376 for Sokoto, 0.463 for Kaduna, and 0.449 for Kano) and highest coefficient of determination, $R^{2}$ values of $0.922,0.938$, and 0.961 for Sokoto, Kano, and Kaduna, respectively. Also, the comparative study result indicates that the estimated global radiation from the proposed model has a better error range and fits the ground measured data better than the satellite-derived data.
\end{abstract}

\section{Introduction}

Solar radiation is the most important source of energy on earth because it plays a major role in sustaining all the activities and processes that support life of both plants and animals on earth. Solar radiation data are needed in a variety of technological areas: agriculture, engineering, forestry, meteorology, water resources management, and the designing and sizing of solar energy systems. Among the various professionals that use solar radiation data, solar energy devices design experts are more concerned about the accuracy of the data since efficient design, sizing, and performance of solar energy devices depend on the accuracy of the available insolation data of the site.

One of the ways of getting accurate and reliable global solar radiation data for solar energy system design is by ground measurements at the site of interest. Ground measurements are typically pin point measurements which are temporally integrated. This involves installation of solar sensor such as pyranometer for continuous, long-term measurements of solar data. Compared to the measurements of other meteorological parameters, the equipment for solar radiation measurements is very expensive and requires experts for operation and maintenance. Although ground measure data are said to be accurate and reliable, the cost implication and technicality involved have made such data unavailable in many locations. This has led to the search for alternative means of getting solar data for research and development of solar energy systems.

Reference [1] identified three classes of methods generally used in getting global solar radiation data apart from direct ground measurements. The first class uses empirical approach where meteorological data are employed with regression techniques. The second class uses solar constant by considering the depletion of insolation value due to clearness index variation and the third class is based on satellite measurements. The first and second classes above (fall under) are classified as global solar radiation estimation techniques. 
TABLE 1: Geographical locations of the studied sites.

\begin{tabular}{lcc}
\hline Location & Latitude & Longitude \\
\hline Sokoto & $13.05^{\circ} \mathrm{N}$ & $5.15^{\circ} \mathrm{E}$ \\
Kano & $12.00^{\circ} \mathrm{N}$ & $8.31^{\circ} \mathrm{E}$ \\
Kaduna & $10.31^{\circ} \mathrm{N}$ & $7.26^{\circ} \mathrm{E}$ \\
\hline
\end{tabular}

Angstrom proposed the first model for estimating monthly average daily global solar radiation in 1924 . Ever since, many of such models have been developed and tested by researchers around the world. Several of these models have been reported for their accuracy in predicting global solar radiation in different locations across the globe [2-6].

Satellite-derived data classified as the third class sources are instantaneous spatial averages remotely measured several kilometres from the earth's surface by geostationary and polar orbiting satellites. Satellite measurements provide easy access to long-term, cheap, and verifiable means of deriving regular solar radiation data for any desired location in the world. Satellite-derived data fit better to a selected site than ground measurements from a site farther than $25 \mathrm{~km}$ away [7]. The ground measured and satellite-derived solar radiation data complement each other and are required to build a comprehensive solar radiation database. It is difficult to have high capability solar radiation monitoring network, and accuracy of the interpolation of data decreases with the increase in distance between sites. Satellite measurements are not as accurate as ground measurements and short time interval data are needed for the engineering and site-specific studies. Hence, combining these two, ground-based and satellite- derived measurements create a comprehensive solar radiation database [8].

The availability of ground measured solar radiation data is not guaranteed for all locations. Likewise meteorological parameters required for estimating global solar radiation data may not be easy to come by in some locations but satellitederived data are available for every location in the world. The focus of this study is therefore to compare the following: (i) the performance of some global solar radiation models and (ii) estimated global solar radiation data and satellitederived data with ground measured data so as to determine their relative levels of accuracy and reliability for solar energy system design and sizing.

\section{Research Methodology}

2.1. Study Area. Three locations from the North-Western region of Nigeria were selected for this study. The geographical locations of the sites are shown in Table 1.

2.2. Data Collection. The twenty-two years' (1984-2005) meteorological data consisting of monthly mean daily sunshine duration, minimum and maximum temperatures, and global solar radiation used for this study were collected from two data sources: the Nigerian Meteorological (NIMET) Agency, Oshodi, Lagos, and the archives of the National Aeronautics Space Agency (NASA).
2.3. Data Analysis Techniques. Microsoft Excel software package was used for the collation of the monthly mean values of the data collected from NIMET and in carrying out other statistical analysis and computation.

2.4. Models for Estimating Global Solar Radiation. The solar radiation data for the selected sites were estimated from sunshine duration and air temperature using the AngstromPrescott model, Garcia model, and a newly developed model incorporating Angstrom-Prescott and Garcia models. The three models were used to allow for comparison of their relative performance in the context of the research.

2.4.1. Angstrom-Prescott Model. The first model for estimating the monthly average daily global solar radiation was proposed by Angstrom in 1924. The proposed relation was deduced based on a correlation between the ratios of average daily global radiation to the corresponding value on an entirely clear day. In 1940, Prescott modified the Angstrom relation with a view to resolving the ambiguity characterizing the definition of the clear sky global solar radiation. The modified version is known as Angstrom-Prescott model. The Angstrom-Prescott model and its corresponding equations are presented in (1)-(5) as given by [9]

$$
\frac{H}{H_{o}}=a+b \frac{S}{S_{o}} .
$$

The values of $H_{o}$ can be calculated using the equation given by $[10]$ as

$$
\begin{aligned}
H_{o}= & \frac{24 \times 3600}{\pi} \times I_{\text {SC }}\left[1.0+0.033 \cos \left(\frac{360 \mathrm{dn}}{365}\right)\right] \\
& \times\left[\cos \emptyset \cos \delta \sin \omega_{S}+\frac{\pi}{180} \omega_{S} \sin \delta \sin \emptyset\right],
\end{aligned}
$$

where $\omega_{S}$ is sunset hour angle in degree defined as

$$
\omega_{S}=\cos ^{-1}(-\tan \emptyset \tan \delta) ;
$$

$\delta$ is declination angle given as

$$
\delta=23.45 \sin \left[\frac{360(284+\mathrm{dn})}{365}\right] ;
$$

$\emptyset$ is the latitude of the location; $\mathrm{dn}$ is day number of the year starting from the first of January; $I_{\mathrm{SC}}$ is solar constant given as $1367\left(\mathrm{Wm}^{-2}\right) ; H$ is monthly average daily global radiation on a horizontal surface $\left(\mathrm{MJm}^{-2} \mathrm{day}^{-1}\right) ; H_{o}$ is monthly average daily extraterrestrial radiation on a horizontal surface; $S$ is monthly average daily number of hours of bright sunshine; $S_{o}$ is monthly average daily maximum number of hours of possible sunshine given as

$$
\left(S_{o}=\frac{2}{15} \omega_{S}\right) ;
$$

$a, b$ are regression constants to be determined. 
2.4.2. Garcia Model. Garcia proposed a model for estimating global solar radiation in 1994. Garcia model is an adaptation of Angstrom-Prescott model with a slight modification that makes it temperature-based type as described in

$$
\frac{H}{H_{o}}=a+b\left(\frac{\Delta T}{S_{o}}\right),
$$

where $a, b$ are regression constants to be determined and $\Delta T$ is the difference between maximum and minimum temperature values.

2.4.3. Proposed Model. A multilinear two-parameter regression model was developed for the estimation of global solar radiation in the selected sites. Garcia model was incorporated into Angstrom-Prescott model to form a new model with three regression constants. The proposed model is of the form:

$$
\frac{H}{H_{o}}=a+b\left(\frac{S}{S_{o}}\right)+c\left(\frac{\Delta T}{S_{o}}\right)
$$

where $a, b$, and $c$ are the regression constants to be determined. All other symbols remain as earlier defined.

2.5. Statistical Analysis of the Empirical Models. Statistical indicators which include mean bias error (MBE), mean percentage error (MPE), root mean square error (RMSE), coefficient of correlation $(R)$, and coefficient of determination $\left(R^{2}\right)$ were used to test the accuracy of the estimated values. The comparison of the satellite-based data and estimated global radiation values with the ground measured data was done using percentage error.

The expressions for the $\mathrm{MBE}\left(\mathrm{MJm}^{-2} \mathrm{day}^{-1}\right), \mathrm{MPE}$ $\left(\mathrm{MJm}^{-2} \mathrm{day}^{-1}\right)$, and RMSE $\left(\mathrm{MJm}^{-2} \mathrm{day}^{-1}\right)$ as stated by [11] are

$$
\begin{aligned}
\mathrm{MBE} & =\frac{\left[\sum\left(H_{i \text { est }}-H_{\text {imeas }}\right)\right]}{n}, \\
\mathrm{MPE} & =\frac{\left[\sum\left(\left(H_{\text {imeas }}-H_{\text {iest }}\right) / H_{\text {imeas }} \times 100\right)\right]}{n}, \\
\mathrm{RMSE} & =\left[\frac{\sum\left(H_{\text {iest }}-H_{\text {imeas }}\right)^{2}}{n}\right]^{1 / 2}, \\
R & =\frac{\left[\sum\left(H_{\text {iest }}-\bar{H}_{\text {iest }}\right)\left(H_{\text {imeas }}-\bar{H}_{\text {imeas }}\right)\right]}{\sqrt{\sum\left(H_{\text {iest }}-\bar{H}_{\text {iest }}\right)^{2} \sum\left(H_{\text {imeas }}-\bar{H}_{\text {imeas }}\right)^{2}}},
\end{aligned}
$$

where $H_{i \text { est }}, H_{\text {imeas }}, \bar{H}_{i \text { est }}$, and $\bar{H}_{i \text { meas }}$ are $i$ th estimated, measured, mean estimated, and mean measured values, respectively, of solar radiation and $n$ is the total number of observations.

MBE and MPE provide information on the long-term performance of models. A positive value and a negative value of $\mathrm{MBE}$ and $\mathrm{MPE}$ indicate the average amount of overestimation and underestimation in the calculated values, respectively. RMSE provides information on shortterm performance of the models. It is always positive. It is recommended that a zero value for MBE is ideal while a low RMSE is desirable [12-14]. The $R$-value defines the linear relationship between the measured and estimated values of global solar radiations while $R^{2}$ statistic gives the percentage variation of the dependent variable in connection with the independent variables. For better modelling, $R$ and $R^{2}$ should approach unity as closely as possible [6].

\section{Result and Discussion}

The regression constants for the proposed model as well as those of Angstrom-Prescott and Garcia models were obtained using IBM SPSS 20 software. Linear regressions were carried out between the monthly observed clearness index and other meteorological parameters using 15 years' data (19841998). The values of the regression constants obtained were substituted into (1), (6), and (7). The modified equations of Angstrom-Prescott model, Garcia model, and the proposed model, respectively, obtained are presented below.

Modified Models Equations for Sokoto

$$
\begin{aligned}
\frac{H}{H_{o}} & =0.250+0.522\left(\frac{S}{S_{o}}\right), \\
\frac{H}{H_{o}} & =0.346+0.217\left(\frac{\Delta T}{S_{o}}\right), \\
\frac{H}{H_{o}} & =0.253+0.232\left(\frac{S}{S_{o}}\right)+0.167\left(\frac{\Delta T}{S_{o}}\right) .
\end{aligned}
$$

Modified Models Equations for Kano

$$
\begin{aligned}
\frac{H}{H_{o}} & =0.314+0.491\left(\frac{S}{S_{o}}\right), \\
\frac{H}{H_{o}} & =0.430+0.176\left(\frac{\Delta T}{S_{o}}\right), \\
\frac{H}{H_{o}} & =0.386+0.081\left(\frac{S}{S_{o}}\right)+0.170\left(\frac{\Delta T}{S_{o}}\right) .
\end{aligned}
$$

Modified Models Equations for Kaduna

$$
\begin{aligned}
\frac{H}{H_{o}} & =0.315+0.433\left(\frac{S}{S_{o}}\right), \\
\frac{H}{H_{o}} & =0.343+0.232\left(\frac{\Delta T}{S_{o}}\right), \\
\frac{H}{H_{o}} & =0.316+0.265\left(\frac{S}{S_{o}}\right)+0.099\left(\frac{\Delta T}{S_{o}}\right) .
\end{aligned}
$$

The global solar radiation for the three selected locations was estimated using the modified equations of the three models as presented in (9)-(11). Long-term average (22 years) sunshine duration and air temperature (maximum and minimum temperatures) data obtained from NIMET were used as input parameters for the models. The input parameters used in this analysis are presented in Table 2.

A comparison of the monthly mean values of the estimated global solar radiation from the three models 
TABLE 2: Monthly mean meteorological data used as input parameters for the models.

\begin{tabular}{|c|c|c|c|c|c|c|c|c|c|}
\hline \multirow{2}{*}{ Month } & \multicolumn{3}{|c|}{ Sokoto } & \multicolumn{3}{|c|}{ Kano } & \multicolumn{3}{|c|}{ Kaduna } \\
\hline & $S(\mathrm{hr})$ & $T_{\max }\left({ }^{\circ}\right)$ & $T_{\min }\left({ }^{\circ}\right)$ & $S(\mathrm{hr})$ & $T_{\max }\left({ }^{\circ}\right)$ & $T_{\min }\left({ }^{\circ}\right)$ & $S(\mathrm{hr})$ & $T_{\max }\left({ }^{\circ}\right)$ & $T_{\min }\left({ }^{\circ}\right)$ \\
\hline Jan & 7.51 & 32.39 & 17.46 & 7.50 & 29.30 & 14.23 & 8.68 & 31.30 & 15.34 \\
\hline Feb & 8.45 & 35.25 & 20.03 & 7.72 & 32.06 & 16.57 & 9.06 & 33.50 & 18.00 \\
\hline Mar & 7.01 & 38.63 & 24.37 & 7.17 & 36.47 & 21.33 & 8.09 & 36.00 & 21.21 \\
\hline Apr & 7.20 & 40.57 & 26.58 & 7.37 & 39.08 & 24.69 & 7.75 & 35.58 & 22.76 \\
\hline May & 7.25 & 38.73 & 26.99 & 8.00 & 38.01 & 24.97 & 7.72 & 33.13 & 22.01 \\
\hline June & 7.52 & 35.84 & 25.29 & 8.28 & 34.74 & 23.49 & 7.53 & 30.50 & 20.71 \\
\hline July & 6.89 & 32.64 & 23.45 & 7.18 & 31.62 & 21.78 & 5.34 & 28.91 & 20.42 \\
\hline Aug & 6.98 & 31.76 & 23.11 & 7.18 & 30.74 & 23.21 & 4.40 & 28.40 & 20.26 \\
\hline Sept & 8.00 & 33.46 & 23.32 & 7.68 & 32.11 & 21.69 & 5.84 & 30.01 & 19.98 \\
\hline Oct & 8.52 & 36.45 & 22.8 & 7.77 & 33.51 & 20.92 & 8.12 & 31.79 & 19.40 \\
\hline Nov & 8.60 & 35.88 & 19.94 & 8.24 & 33.07 & 17.10 & 9.20 & 32.93 & 16.33 \\
\hline Dec & 8.00 & 32.92 & 17.60 & 7.44 & 29.41 & 14.23 & 9.14 & 31.26 & 14.92 \\
\hline
\end{tabular}

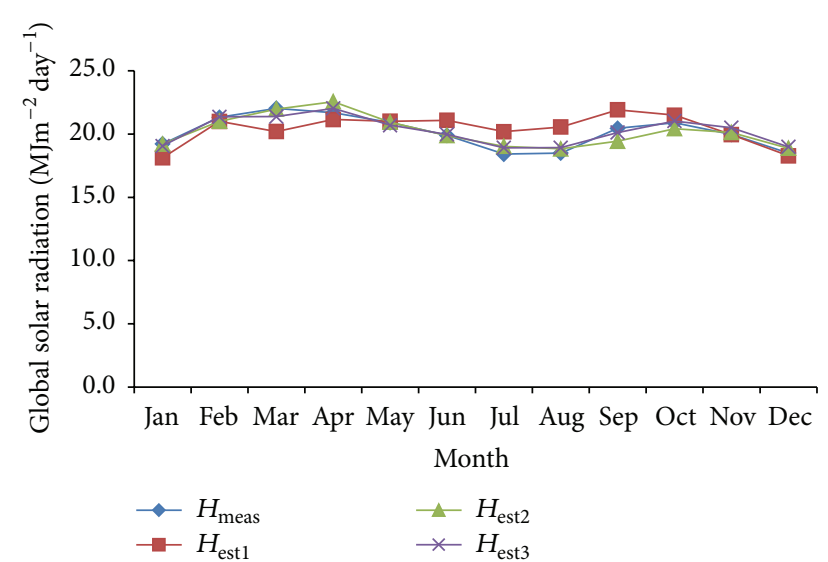

FIGURE 1: Estimated and ground measured global solar radiation for Sokoto.

with ground measured data for Sokoto, Kaduna, and Kano is shown in Figures 1-3. $H_{\text {meas }}$ represents ground measured data, while $H_{\text {est1 }}, H_{\text {est2 }}$, and $H_{\text {est3 } 3}$ represent estimated global solar radiation from Angstrom-Prescott model, Garcia model, and the proposed model, respectively.

From Figures $1-3$, it can be observed that $H_{\text {est3 }}$ shows better agreement with the measured data than $H_{\text {est } 2}$ and $H_{\text {est } 1}$ in the three locations. Angstrom-Prescott model $\left(H_{\text {est } 1}\right)$ shows the highest level of overestimation and underestimation among the three models used. This indicates that the proposed model is better than Angstrom-Prescott model and Garcia model in predicting the monthly mean global solar radiation in the selected locations.

3.1. Statistical Error Indicators of the Studied Models. The calculated values of the error indices of the studied models for the three locations are summarised in Table 3. As stated earlier, a low RMSE is desirable while $R$ and $R^{2}$ should approach unity as closely as possible. A positive value or a negative value of MBE and MPE indicate overestimation or underestimation in the calculated values, respectively.

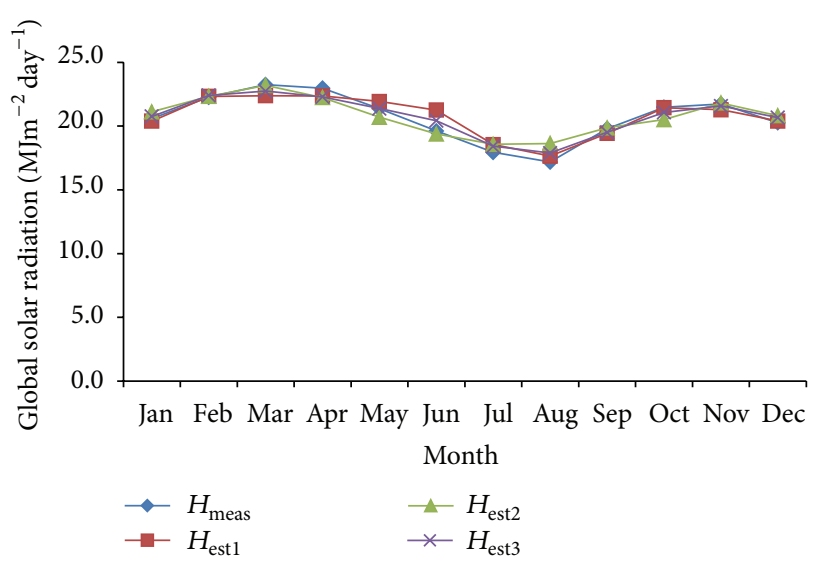

FIGURE 2: Estimated and ground measured global solar radiation for Kaduna.

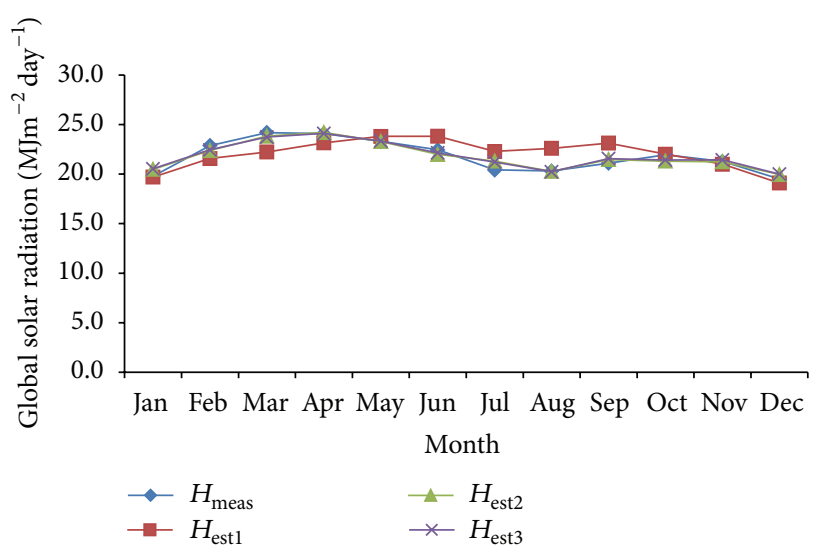

FIGURE 3: Estimated and ground measured global solar radiation for Kano.

It is observed from Table 3 that the error indices of the studied models vary from one location to another. This could be due to the variability in the atmospheric parameters which influences the solar radiation in those locations. On 
TABLE 3: Statistical error indicators of global solar radiation models.

\begin{tabular}{|c|c|c|c|c|c|c|}
\hline State & Model & $\mathrm{MBE}$ & MPE & RMSE & $R$ & $R^{2}$ \\
\hline \multirow{3}{*}{ Sokoto } & Model 1 & 0.264 & -1.501 & 1.167 & 0.534 & 0.285 \\
\hline & Model 2 & 0.042 & -0.254 & 0.483 & 0.920 & 0.846 \\
\hline & Model 3 & 0.098 & -0.555 & 0.376 & 0.960 & 0.922 \\
\hline \multirow{3}{*}{ Kaduna } & Model 1 & 0.077 & -0.544 & 0.654 & 0.938 & 0.879 \\
\hline & Model 2 & 0.056 & -0.482 & 0.652 & 0.944 & 0.892 \\
\hline & Model 3 & 0.054 & -0.420 & 0.463 & 0.980 & 0.961 \\
\hline \multirow{3}{*}{ Kano } & Model 1 & 0.263 & -1.420 & 1.337 & 0.616 & 0.379 \\
\hline & Model 2 & 0.042 & -0.290 & 0.466 & 0.961 & 0.923 \\
\hline & Model 3 & 0.077 & -0.457 & 0.449 & 0.969 & 0.938 \\
\hline
\end{tabular}

TABLE 4: Comparison of monthly mean ground measured solar radiation and satellite data $\left(\mathrm{MJm}^{-2} \mathrm{day}^{-1}\right)$.

\begin{tabular}{|c|c|c|c|c|c|c|c|c|c|}
\hline \multirow{2}{*}{ Month } & \multicolumn{3}{|c|}{ Sokoto } & \multicolumn{3}{|c|}{ Kano } & \multicolumn{3}{|c|}{ Kaduna } \\
\hline & $H_{\text {meas }}$ & $H_{\text {sat }}$ & $\%$ error & $H_{\text {meas }}$ & $H_{\text {sat }}$ & $\%$ error & $H_{\text {meas }}$ & $H_{\text {sat }}$ & $\%$ error \\
\hline Jan & 19.22 & 19.69 & 2.4 & 19.79 & 19.76 & -0.2 & 20.59 & 20.74 & 0.7 \\
\hline Feb & 21.32 & 23.08 & 8.3 & 22.87 & 22.79 & -0.3 & 22.26 & 21.82 & -2.0 \\
\hline Mar & 22.03 & 24.73 & 12.3 & 24.18 & 24.44 & 1.1 & 23.25 & 22.75 & -2.2 \\
\hline Apr & 21.68 & 25.74 & 18.7 & 24.08 & 25.06 & 4.1 & 22.97 & 22.68 & -1.3 \\
\hline May & 20.91 & 25.31 & 21.0 & 23.30 & 24.34 & 4.5 & 21.37 & 21.38 & 0.0 \\
\hline Jun & 19.90 & 24.88 & 25.0 & 22.45 & 23.11 & 2.9 & 19.62 & 19.44 & -0.9 \\
\hline Jul & 18.41 & 22.54 & 22.4 & 20.42 & 20.92 & 2.4 & 17.94 & 17.46 & -2.7 \\
\hline Aug & 18.50 & 20.63 & 11.5 & 20.31 & 19.48 & -4.1 & 17.18 & 16.09 & -6.3 \\
\hline Sep & 20.45 & 21.64 & 5.8 & 21.10 & 20.41 & -3.3 & 19.80 & 18.4 & -7.1 \\
\hline Oct & 20.90 & 21.71 & 3.9 & 21.94 & 21.24 & -3.2 & 21.48 & 20.27 & -5.6 \\
\hline Nov & 19.97 & 20.84 & 4.4 & 21.27 & 20.59 & -3.2 & 21.74 & 22.00 & 1.2 \\
\hline Dec & 18.50 & 18.90 & 2.2 & 19.50 & 18.97 & -2.7 & 20.26 & 20.84 & 2.9 \\
\hline Average & 20.15 & 22.47 & 11.5 & 21.77 & 21.76 & -0.2 & 20.71 & 20.32 & -1.9 \\
\hline
\end{tabular}

the long-term performance of the models, the MBE and MPE values for the three models show slight overestimation and slight underestimation of the estimated global solar radiation, respectively. However, it can be noted that Angstrom-Prescott model gave the highest values of MBE and MPE in all the locations. This indicates a poor performance of the model on long-term basis.

The proposed model (model 3) gave the lowest RMSE values in the three locations ( 0.376 for Sokoto, 0.463 for Kaduna, and 0.449 for Kano) while model 1 (AngstromPrescott model) produced the highest RMSE values in the range $0.654-1.337$. The statistical error indices presented in Table 3 also shows that model 3 and model 2 have higher values of coefficient of correlation $(R)$ and coefficient determination $\left(R^{2}\right)$ when compared to model 1 . However, model 3 produced the highest $R^{2}$ values in all the locations (0.922 for Sokoto, 0.938 for Kano, and 0.961 for Kaduna). The $R^{2}$ value of 0.961 shows that $96.1 \%$ of the clearness index for Kaduna is accounted for by model 3. The coefficient of determination, with $R^{2}$ values of $0.922-0.961$ obtained for model 3, indicates that this model fits the data very well. This implies that the monthly mean global solar radiation estimated from Model 3 are more accurate than the monthly mean global solar radiation estimated from models 1 and 2 . Also, it can be concluded base on the result of the statistical error indicators that Model 2 (Garcia model) performed better than model 1 (Angstrom-Prescott model) in the study locations. However, it is noteworthy that the inclusion of air temperature to Angstrom-Prescott model (1) in the proposed model (equation (7)) has a significant impact on the accuracy of the sunshine-based model. This is in agreement with [6] where the inclusion of air temperature as input parameter improves the performance of global solar radiation in areas with high-temperature difference.

On the whole, it could be observed that model 3 gives the best error estimates in terms of RMSE and the highest $R^{2}$ values too. This implies that model 3 has the overall best performance among the three studied models. Hence, the proposed model (model 3) is recommended for estimating the monthly mean daily global solar radiation on the horizontal surface in Sokoto, Kano, Kaduna, and other locations with similar meteorological parameters.

3.2. Comparison of Ground Measurements with Estimated Values and Satellite Data. The monthly mean values of the twenty-two years (1984-2005) global solar radiation data obtained from NIMET were compared with estimated values from the proposed model and satellite-derived data spanning the same years. Tables 4 and 5 present the summary of the comparison in terms of their percentage error. From Table 4, 
TABLE 5: Comparison of monthly mean ground measured solar radiation and estimated values $\left(\mathrm{MJm}^{-2} \mathrm{day}^{-1}\right)$.

\begin{tabular}{|c|c|c|c|c|c|c|c|c|c|}
\hline \multirow{2}{*}{ Month } & \multicolumn{3}{|c|}{ Sokoto } & \multicolumn{3}{|c|}{ Kano } & \multicolumn{3}{|c|}{ Kaduna } \\
\hline & $H_{\text {meas }}$ & $H_{\mathrm{est}}$ & $\%$ error & $H_{\text {meas }}$ & $H_{\text {est }}$ & $\%$ error & $H_{\text {meas }}$ & $H_{\text {est }}$ & $\%$ error \\
\hline Jan & 19.22 & 19.06 & -0.8 & 19.79 & 20.53 & 3.7 & 20.59 & 20.76 & 0.8 \\
\hline Feb & 21.32 & 21.36 & 0.2 & 22.87 & 22.45 & -1.8 & 22.26 & 22.4 & 0.6 \\
\hline Mar & 22.03 & 21.38 & -3.0 & 24.18 & 23.73 & -1.9 & 23.25 & 22.74 & -2.2 \\
\hline Apr & 21.68 & 22.03 & 1.6 & 24.08 & 24.1 & 0.1 & 22.97 & 22.29 & -3.0 \\
\hline May & 20.91 & 20.7 & -1.0 & 23.30 & 23.33 & 0.1 & 21.37 & 21.38 & 0.0 \\
\hline Jun & 19.90 & 19.97 & 0.4 & 22.45 & 22.13 & -1.4 & 19.62 & 20.42 & 4.1 \\
\hline Jul & 18.41 & 18.91 & 2.7 & 20.42 & 21.21 & 3.9 & 17.94 & 18.42 & 2.7 \\
\hline Aug & 18.50 & 18.92 & 2.3 & 20.31 & 20.24 & -0.3 & 17.18 & 17.88 & 4.1 \\
\hline Sep & 20.45 & 20.12 & -1.6 & 21.10 & 21.56 & 2.2 & 19.80 & 19.51 & -1.5 \\
\hline Oct & 20.90 & 21.03 & 0.6 & 21.94 & 21.42 & -2.4 & 21.48 & 21.07 & -1.9 \\
\hline Nov & 19.97 & 20.5 & 2.7 & 21.27 & 21.43 & 0.8 & 21.74 & 21.58 & -0.7 \\
\hline Dec & 18.50 & 18.99 & 2.6 & 19.50 & 20 & 2.6 & 20.26 & 20.66 & 2.0 \\
\hline Average & 20.15 & 20.25 & 0.6 & 21.77 & 21.84 & 0.5 & 20.71 & 20.76 & 0.4 \\
\hline
\end{tabular}

it can be observed that the satellite-derived global solar radiation data exceeds the ground measurements in all the months of the year with percentage error ranging from $2.2 \%$ to $25.0 \%$ in Sokoto. Kano has an average percentage error margin of $-0.2 \%$ which indicates that the variation between the ground measurements and satellite data is minimal. For Kaduna, the percentage error is maximum in December being $2.9 \%$ and minimum in September being $-7.1 \%$.

Moreover, in comparing the ground measurements with the estimated global solar radiation, Table 5 reveals that the percentage error calculated for Sokoto, Kano, and Kaduna were in the range $-3.0 \%$ to $2.7 \%,-2.4 \%$ to $3.7 \%$ and $-3.0 \%$ to $4.1 \%$, respectively.

Summarily, the satellite-derived data has error range of $-7.1 \%$ to $25.0 \%$ (Table 4 ), while the estimated global radiation has error range of $-3.0 \%$ to $4.1 \%$ (Table 5 ). It can be inferred that the estimated global radiation has a better error range. Hence, the estimated global solar radiation values compared favourably with the ground measurements compared to the satellite-derived data.

A comparison of the 22 years (1984-2005) average annual global solar radiation estimated from model 3 and satellitebased data with ground measured global solar radiation for the study locations is presented in Figure 4.

Figure 4 shows that the annual mean values of the estimated global solar radiation correspond with the ground measurements in all the locations. In the case of the satellitederived data, the annual mean values are higher and slightly lower than the ground measurements in Sokoto and Kaduna, respectively, but correspond with the ground measurement in Kano. Therefore, estimated global solar radiation values obtained from the proposed model are more accurate and reliable for the design and sizing of solar energy devices than the satellite-derived data.

\section{Conclusion}

Accurate and reliable solar radiation data is necessary for the design of solar energy devices. Hence, the need to develop

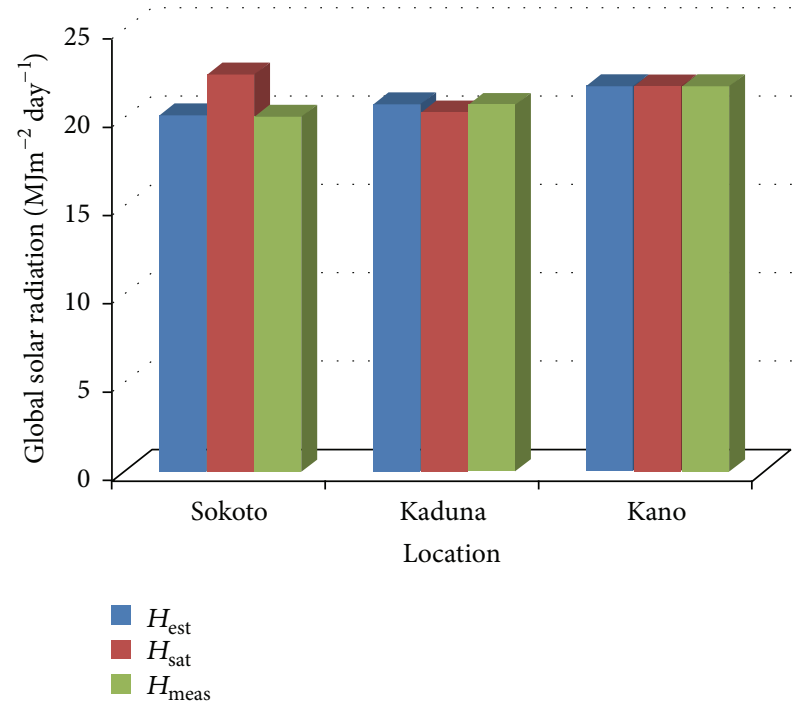

Figure 4: Comparison of the 22 years' (1984-2005) Annual Mean Global Solar Radiation.

model with high level of accuracy for estimating global solar radiation and to compare the solar radiation data generated from different sources to determine their level of accuracy. In this study, Garcia model was incorporated into AngstromPrescott model to form a new model in the form:

$$
\frac{H}{H_{o}}=a+b\left(\frac{S}{S_{o}}\right)+c\left(\frac{\Delta T}{S_{o}}\right) .
$$

The proposed model when compared with Garcia and Angstrom-Prescott models was found to have the best accuracy with the least RMSE values ( 0.376 for Sokoto, 0.463 for Kaduna, and 0.449 for Kano) and highest coefficient of determination, $R^{2}$ values of $0.922,0.938$, and 0.961 for Sokoto, Kano, and Kaduna, respectively. The result shows that the proposed model is suitable for estimating global solar 
radiation in the North-Western region of Nigeria and other locations with similar meteorological parameters.

Also, the result of the comparative study of the estimated and satellite-derived data with ground measured global solar radiation data indicates that the

(i) estimated global radiation has a better error range $(-3.0 \%$ to $4.1 \%)$ than the satellite-derived data with error range of $-7.1 \%$ to $25.0 \%$,

(ii) estimated global solar radiation from the proposed model fits the ground measured data better than the satellite-derived data in the three study sites,

(iii) estimated global solar radiation values obtained from the proposed model can be used for the design and sizing of solar energy devices in the study areas.

\section{Competing Interests}

The authors declare that there is no conflict of interests regarding the publication of this paper.

\section{Acknowledgments}

The authors are grateful to the management of Nigerian Meteorological (NIMET) agency, Oshodi, Lagos, and the National Aeronautics Space Agency (NASA) for making available the metrological data used in this work.

\section{References}

[1] A. S. Sambo and M. D. C. Doyle, "The correlation of global and diffuse solar radiation components with meteorological data for Zaria," Nigerian Journal of Solar Energy, vol. 7, 1988.

[2] J. K. Page, "The estimation of monthly mean values of daily total short wave radiation on vertical and inclined surfaces from sunshine records for latitudes $40^{\circ} \mathrm{N}-40^{\circ} \mathrm{S}$," in Proceedings of the United Nations Conference on New Sources of Energy, pp. 378390, Rome, Italy, August 1961.

[3] M. R. Rietveld, "A new method for estimating the regression coefficients in the formula relating solar radiation to sunshine," Agricultural Meteorology, vol. 19, no. 2-3, pp. 243-252, 1978.

[4] G. H. Hargreaves and Z. A. Samani, "Estimating potential evapotranspiration," Journal of Irrigation and Drainage Engineering, vol. 108, no. 3, pp. 223-230, 1982.

[5] F. Besharat, A. A. Dehghan, and A. R. Faghih, "Empirical models for estimating global solar radiation: a review and case study," Renewable and Sustainable Energy Reviews, vol. 21, pp. 798-821, 2013.

[6] M. S. Okundamiya, J. O. Emagbetere, and E. A. Ogujor, "Evaluation of various global solar radiation models for Nigeria," International Journal of Green Energy, vol. 13, no. 5, pp. 505-512, 2016.

[7] N. Geuder, Solar Resource Measurements and Satellite Data, 4th Sfera Summer School, Hornberg Castle, Germany, 2013.

[8] I. Karakoti, A. Datta, and S. K. Singh, "Validating satellite-based solar radiation data with ground measurements," Geospatial World Weekly, IGF, Gurgaon, India, 2012.

[9] B. M. Olomiyesan, O. D. Oyedum, P. E. Ugwuoke, J. A. Ezenwora, and A. G. Ibrahim, "Solar energy for power generation: a review of solar radiation measurement processes and global solar radiation modelling techniques," Nigerian Journal of Solar Energy, vol. 26, 2015.

[10] J. A. Duffie and W. A. Beckman, Solar Engineering of Thermal Processes, John Wiley \& Sons, New York, NY, USA, 2nd edition, 1991.

[11] A. A. El-Sebaii and A. A. Trabea, "Estimation of global solar radiation on horizontal surfaces over Egypt," Egypt Journal of Solids, vol. 28, no. 1, pp. 163-175, 2005.

[12] M. Igbal, An Introduction to Solar Radiation, Academy Press, New York, NY, USA, 1983.

[13] L. E. Akpabio and S. E. Etuk, "Relationship between global solar radiation and sunshine duration for Onne, Nigeria," Turkish Journal of Physics, vol. 27, no. 2, pp. 161-167, 2003.

[14] G. N. Okonkwo and A. O. C. Nwokoye, "Estimating global solar radiation from temperature data in Minna location," European Scientific Journal, vol. 10, no. 15, pp. 254-264, 2014. 

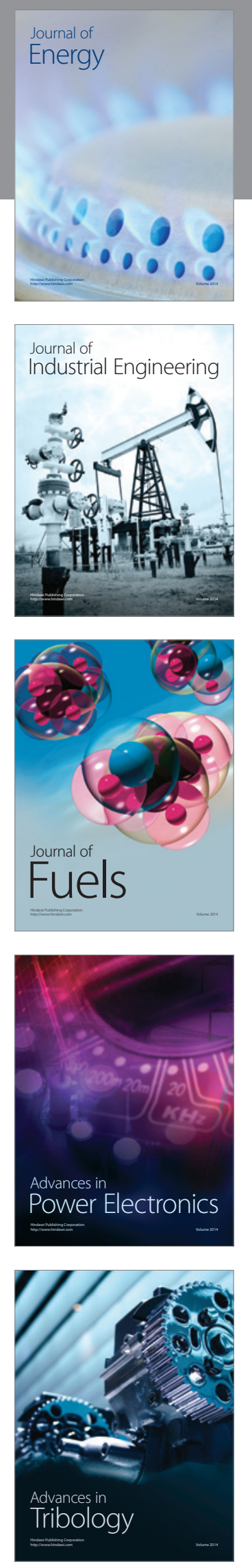
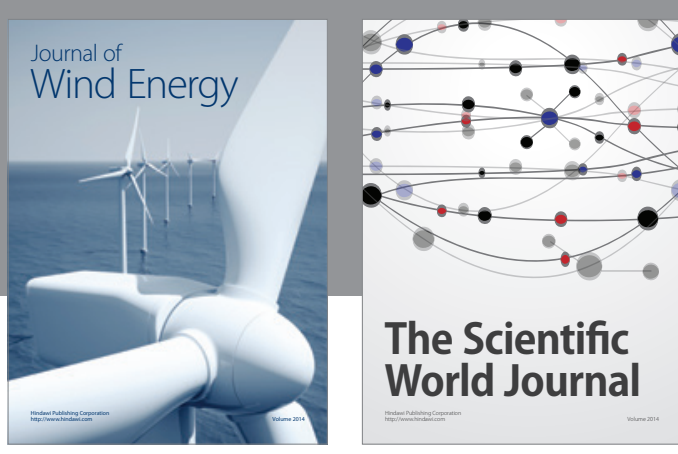

The Scientific World Journal
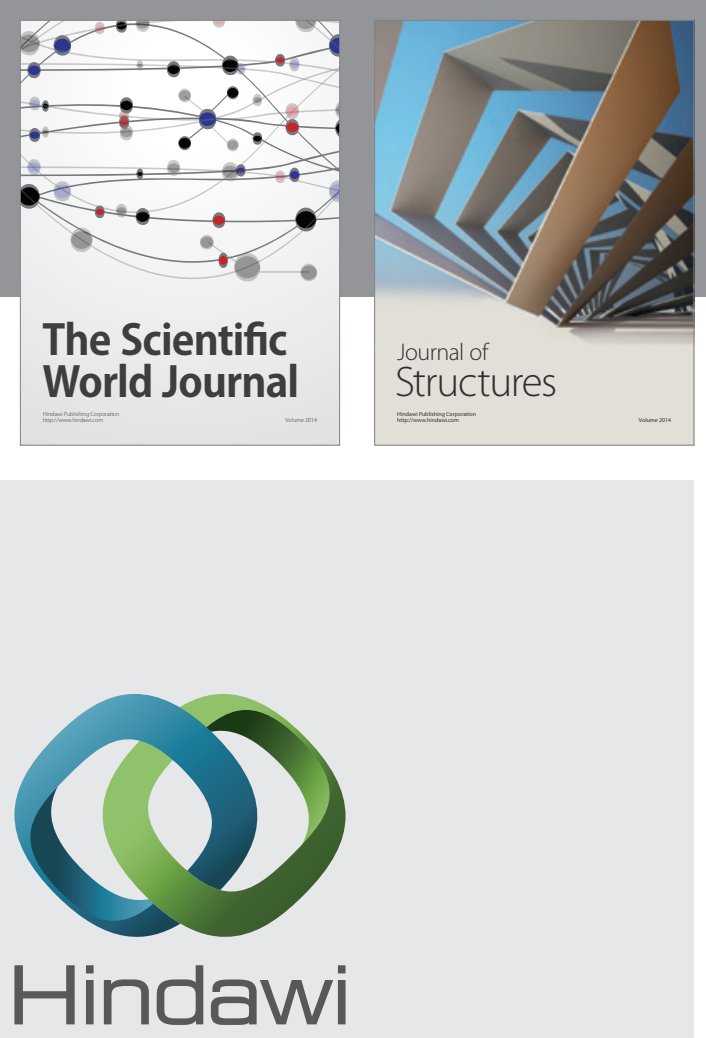

Submit your manuscripts at

http://www.hindawi.com
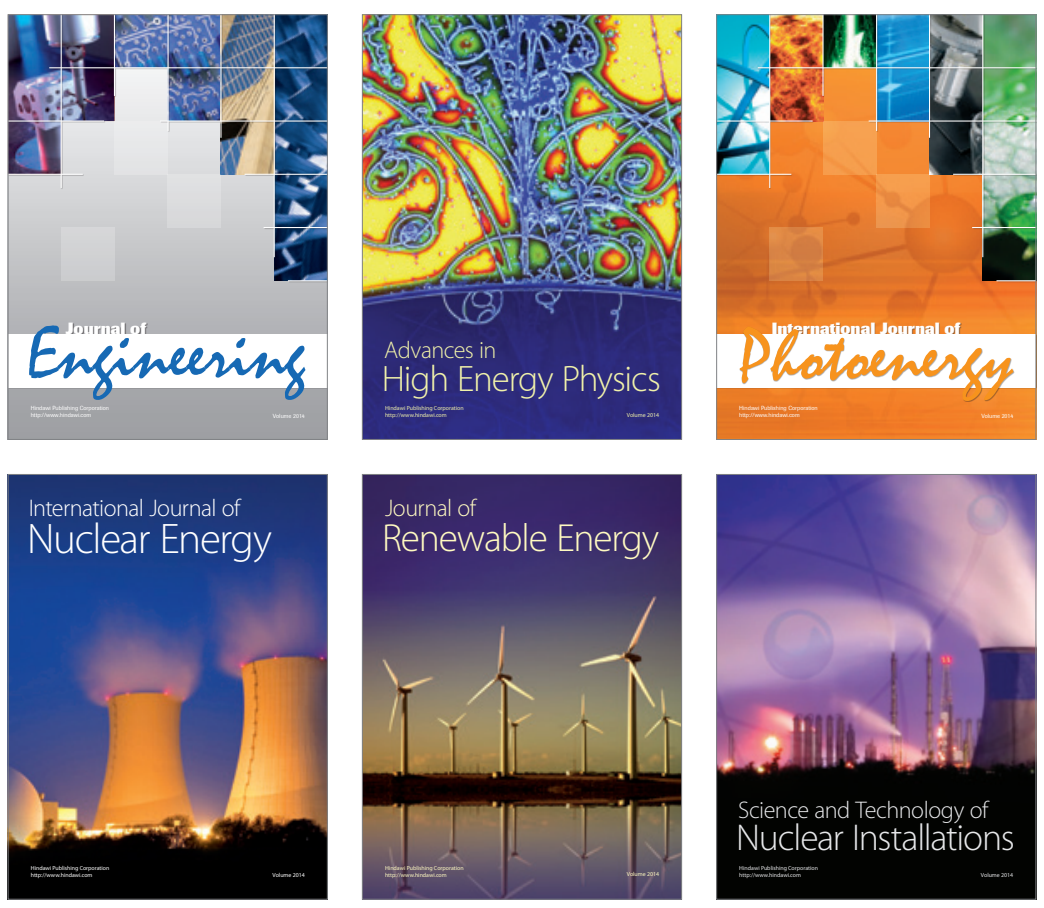
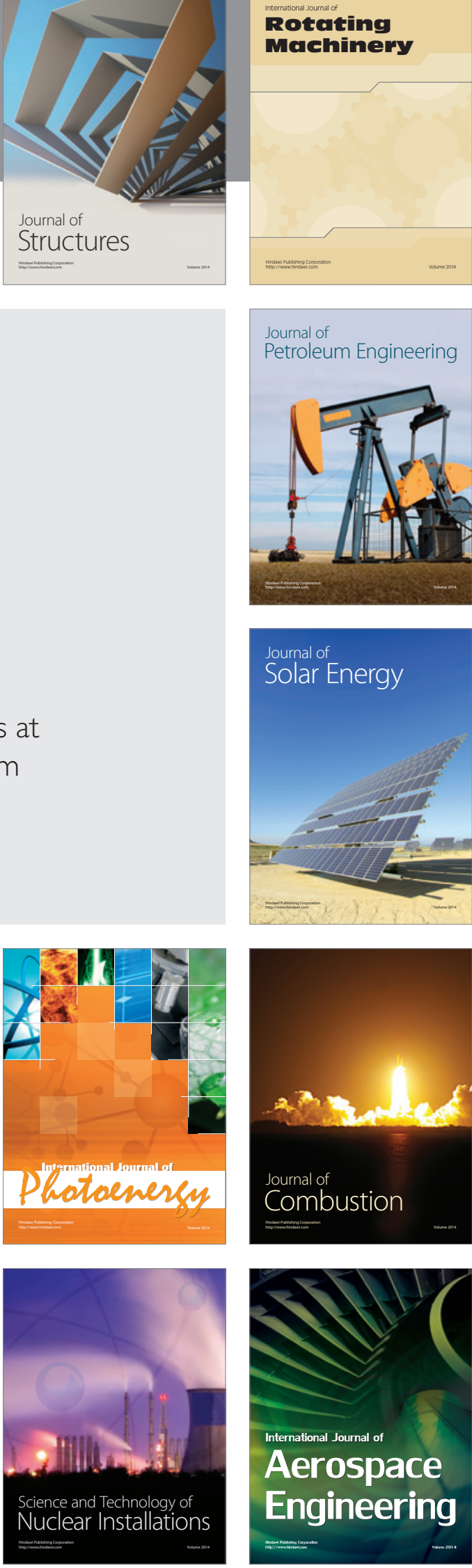